\title{
Effect of surgical margin on postoperative prognosis in patients with solitary hepatocellular carcinoma: A propensity score matching analysis
}

Zewen Zhou ${ }^{1,2}$, Lunan $\mathrm{Qi}^{1}$, Qiuyan Mo ${ }^{1,2}$, Yingchun Liu ${ }^{1}$, Xianguo Zhou' ${ }^{1}$ Zihan Zhou ${ }^{1}$, Xiumei Liang ${ }^{1}$, Shixiong Feng ${ }^{1,2}$, Hongping $\mathrm{Yu}^{1,2} \mathbb{}$

1. Guangxi Medical University Cancer Hospital, Nanning 530021, China.

2. School of Public Health, Guangxi Medical University, Nanning 530021, China.

Zewen Zhou and Lunan Qi contributed equally to this work.

$\triangle$ Corresponding author: Hongping Yu, MD, PhD, Guangxi Medical University Cancer Hospital, Nanning 530021, China, School of Public Health, Guangxi Medical University, Nanning 530021, China. Tel: (+86)0771-5330850; Fax: (+86)0771-5330850; E-mail: yuhongping@stu.gxmu.edu.cn.

(C) The author(s). This is an open access article distributed under the terms of the Creative Commons Attribution License (https://creativecommons.org/licenses/by/4.0/). See http://ivyspring.com/terms for full terms and conditions.

Received: 2021.01.06; Accepted: 2021.05.13; Published: 2021.05.27

\begin{abstract}
Objective: The effect of surgical margin (SM) on the postoperative prognosis of patients with solitary hepatocellular carcinoma (HCC) remains controversial. This study aimed to evaluate the effect of SM on the postoperative prognosis of patients with solitary HCC by using propensity score matching (PSM).

Methods: Patients with solitary HCC who underwent liver resection were divided into a wide margin group $(1.0 \mathrm{~cm}$ or more, group $\mathrm{W})$ and a narrow margin group $(<1.0 \mathrm{~cm}$, group $\mathrm{N})$. Progression-free survival (PFS) and overall survival (OS) associated with the SM status and the factors influencing postoperative prognosis were evaluated.

Results: Before PSM, the indicators were not balanced between the two groups. PFS and OS were significantly lower in group $\mathrm{N}$ than group $\mathrm{W}$. The factors affecting postoperative prognosis were international normalized ratio (INR), AST, capsule integrity, microvascular invasion, tumour embolus and tumour size. After PSM, data of both groups were balanced and comparable, and no significant differences in OS or PFS between the two groups. The INR in the above affecting factors was excluded.

Conclusion: For solitary HCC patients with negative SMs, SM size does not affect prognosis. INR, AST, capsule integrity, microvascular invasion, tumour embolus and tumour size are independent factors influencing the postoperative prognosis of solitary HCC patients.
\end{abstract}

Key words: surgical margin, postoperative prognosis, propensity score matching, hepatocellular carcinoma

\section{Introduction}

A global statistical analysis of tumours in 2018 showed that the number of new-onset liver cancer (LC) cases was 841,080, accounting for $4.65 \%$ of new-onset cancer cases worldwide, and the number of LC-related deaths was 781,631, accounting for $8.18 \%$ of cancer deaths worldwide [1]. The LC incidence and the number of LC cases differ greatly across the world [2]. The LC incidence is the highest in East Asia, Southeast Asia, and sub-Saharan Africa and is low in Europe and America, while China has approximately half of the LC cases worldwide. Hepatitis B virus
(HBV) infection is the leading cause of the high LC incidence in China [3]. Primary LC includes hepatocellular carcinoma (HCC), intrahepatic cholangiocarcinoma, and combined hepatocellular carcinoma and cholangiocarcinoma [4]. Clinically, HCC is the most common type, accounting for $85-90 \%$ of all LC cases.

Because LC usually has a high degree of malignancy, rapid disease progression, and tendentious recurrence and metastasis, it usually has a poor prognosis $[5,6]$. Surgery and liver 
transplantation are still the most important treatment methods for early-stage LC $[7,8]$. Many factors affect the postoperative prognosis of LC patients, such as tumour-node-metastasis (TNM) stage [7], Barcelona Clinic Liver Cancer (BCLC) stage [8, 9], albuminbilirubin (ALBI) score [10], surgical margin (SM) [11-13], degree of tumour differentiation [14], the number of tumours [15], and tumour size [16]. Some of these factors remain controversial. On the one hand, most of the evidence comes from retrospective studies, so the confounding factors have been difficult to control for; on the other hand, prospective studies often have relatively small sample sizes, which reduces the effectiveness of statistical tests.

In Chinese surgical practice, for LC surgery, the SM must be at least $1 \mathrm{~cm}$ away from the tumour. However, in practice, due to the special anatomical location of the tumour (e.g., the tumour is close to a large blood vessel), many patients still have a SM less than $1 \mathrm{~cm}$. A series of studies have examined the effect of SM on the postoperative prognosis of HCC patients. A retrospective study on the postoperative prognosis of HCC patients in Japan showed that SM affected the prognosis of patients with tumour diameter $\leq 4 \mathrm{~cm}$ but had no effect on the prognosis of patients with tumour diameter $>4 \mathrm{~cm}$ [11]. The effect of SM on the prognosis of LC patients was confirmed in another Japanese study, which showed that when tumour size was $\leq 2 \mathrm{~cm}, \mathrm{SM}$ affected the prognosis of LC patients, but SM did not affect the prognosis of LC patients with tumour size $>2 \mathrm{~cm}$ [12]. A study conducted in Taiwan also found a correlation between SM and the prognosis of LC patients [13]. However, two other studies conducted in Taiwan showed that $\mathrm{SM}$ was not associated with postoperative prognosis in LC patients $[17,18]$.

Studies on the correlation between SM and the prognosis of the HCC population in China are still relatively rare. Considering the pathogenesis of LC and the ethnic specificity of China, it is worthwhile to explore the relationship between SM and prognosis in HCC patients in China. In this study, two groups of HCC patients were defined according to SM size, and the confounding factors in the two groups were controlled for by propensity score matching PSM to make the clinical data of the two SM groups balanced and comparable. The relationship between SM and the prognosis of HCC patients was further explored.

\section{Data and methods}

\section{Study subjects}

In a long-term follow-up cohort of HCC patients in the Guangxi Medical University Cancer Hospital, 817 patients who underwent liver resection after an initial diagnosis in our hospital from January 2013 to December 2015 were selected, and their clinical data and follow-up information were collected.

\section{Inclusion and exclusion criteria}

The inclusion criteria were as follows: (1) HCC was confirmed by postoperative pathology; (2) liver function was Child-Pugh A or Child-Pugh B that could be improved to Child-Pugh A, and; (3) no adjuvant therapy was received before surgery. The exclusion criteria were as follows: (1) distant metastasis or advanced HCC; (2) severe heart, lung, kidney, or cerebrovascular diseases; and (3) positive SMs.

\section{Follow-up status}

Start and end of follow-up: The surgery time was taken as the starting point of follow-up. The patients were followed up every 3 months for the first 3 years after surgery, then followed up every 6 months. For the patients who died due to HCC during the follow-up period, the death was the end point, and for the other patients, the end point was December 31, 2019. Postoperative recurrence was defined as two typical imaging findings, one imaging finding + elevated a-fetoprotein (AFP), or positivity on biopsy/resection. For patients with recurrence, treatments such as secondary surgery, radiofrequency ablation, transarterial chemoembolization, sorafenib, and best supportive care were recommended based on the recurrence pattern and functional liver reserve. Overall survival (OS) was defined as the time from first surgery to death from any cause or to the last follow-up for the patients lost to follow-up. Progression-free survival (PFS) was defined as the time from the first surgery to the earliest evidence of recurrence. Among the 817 patients, 78 were lost to follow-up, for a rate of loss to follow-up of $9.55 \%$. If the clinical data of the patients who were lost follow-up were complete, and they were still included to ensure the authenticity of this study.

\section{Definition of SM}

The SM refers to the shortest distance from the edge of the tumour to the resection line. In clinical practice, the SM is usually estimated by the naked eye of the surgeon and measured by a pathologist. For the surgeries included in this study, the surgical sections were consistent, and the SMs were determined by pathologists. The measurement criteria of SMs in the Department of Pathology were as follows: (1) the width of the resection margin was the distance from the tumour margin to the liver parenchyma; (2) for multinodular or satellite lesions, the tumour nodule closest to the edge was used as a reference; and (3) in the measurement of margin width for each 
dimension, the minimum value was defined as the narrowest width.

\section{Grouping}

According to the SM size in the pathology report, the 817 patients were divided into a wide margin group $(1.0 \mathrm{~cm}$ or more, group $\mathrm{W}, \mathrm{n}=325)$ and a narrow margin group ( $<1.0 \mathrm{~cm}$, group $\mathrm{N}, \mathrm{n}=492)$. Group W including 276 males and 49 females, with an average age of $49.27 \pm 10.55$ years. Group $N$ including 407 males and 85 females, with an average age of $49.50 \pm 11.22$ years.

\section{PSM of indicators}

This study matched the indicators from the following four categories: (1) baseline data: age, sex, and body mass index (BMI); (2) chronic diseases: liver cirrhosis, hypertension, and diabetes; (3) routine haematological and biochemical indicators: international normalized ratio (INR), aspartate aminotransferase (AST), alanine aminotransferase (ALT), serum a-fetoprotein (AFP), hepatitis B e-antigen ( $\mathrm{HBeAg})$, hepatitis $B$ surface antigen (HBsAg), and HBV DNA; (4) tumour-related indicators: Edmondson grade, BCLC stage, ALBI score, platelet-to-lymphocyte ratio (PLR), neutrophilto-lymphocyte ratio (NLR), capsule integrity, microvascular invasion, tumour embolus, and tumour size.

The basic information and underlying diseases of patients were obtained from the initial admission records. PLR is calculated as platelet count/ lymphocyte count, and the optimal cut-off value obtained from the receiver operating characteristic (ROC) curve was used to divide the patients in a low PLR group and a high PLR group. NLR is calculated as neutrophil count/lymphocyte count, and the optimal cut-off value obtained from the ROC curve was used to divide the patients in a low NLR group and a high NLR group. ALBI score is calculated as $-0.085 \times$ [albumin $(\mathrm{g} / \mathrm{L})]+0.66 \times \log _{10}[$ bilirubin (mmol/L)] [19], see Table 1 .

\section{Statistical analysis}

SPSS (version 22.0; SPSS Inc., Chicago, IL, USA) was used for statistical analysis. Continuous variables are expressed as the mean \pm standard deviation $(\bar{\chi} \pm$ $s$ ), and the Z-test was used for comparison; the categorical data are expressed as the frequency, and the $X^{2}$ test was used for comparison. PSM was calculated using a logistic regression model, the one-to-one nearest-neighbour matching algorithm was used, the calliper width was 0.2 , and there was no replacement. The balance between the variables of the two groups was evaluated through standardized differences. ${ }^{20}$ The survival analysis was performed using the Kaplan-Meier method, and survival was compared using the log-rank test. A Cox proportional hazard model was used for univariate and multivariate analyses, and potential risk factors $(P<$ $0.05)$ in univariate analysis were input into the Cox regression model. When $P<0.05$, the difference was considered statistically significant.

Table 1. Assignment table of research indexes

\begin{tabular}{|c|c|}
\hline Index & Assignment rules \\
\hline \multicolumn{2}{|l|}{ Baseline data } \\
\hline age & $<60$ year $=1, \geq 60$ year $=2$ \\
\hline sex & male $=1$, female $=2$ \\
\hline BMI & $18.5 \mathrm{~kg} / \mathrm{m}^{2} \sim 23.9 \mathrm{~kg} / \mathrm{m}^{2}=1$, others $=2$ \\
\hline \multicolumn{2}{|l|}{ Chronic diseases } \\
\hline liver cirrhosis & no $=0$, yes $=1$ \\
\hline hypertension & no $=0$, yes $=1$ \\
\hline diabetes & no $=0$, yes $=1$ \\
\hline \multicolumn{2}{|l|}{$\begin{array}{l}\text { Routine haematological and } \\
\text { biochemical indicators }\end{array}$} \\
\hline albumin & $35 \sim 51 \mathrm{~g} / \mathrm{L}=1$, others $=2$ \\
\hline total bilirubin & $3.4 \sim 17.1 \mu \mathrm{mol} / \mathrm{L}=1$, others $=2$ \\
\hline INR & $0.8 \sim 1.2=1$, others $=2$ \\
\hline AST & $\leq 40 \mathrm{U} / \mathrm{L}=1,>40 \mathrm{U} / \mathrm{L}=2$ \\
\hline ALT & $\leq 40 \mathrm{U} / \mathrm{L}=1,>40 \mathrm{U} / \mathrm{L}=2$ \\
\hline AFP & $<400 \mu \mathrm{g} / \mathrm{L}=1, \geq 400 \mu \mathrm{g} / \mathrm{L}=2$ \\
\hline HBeAg & negative $=0$, positive $=1$ \\
\hline HBsAg & negative $=0$, positive $=1$ \\
\hline HBV DNA & negative $=0$, positive $=1$ \\
\hline \multicolumn{2}{|l|}{ Tumour-related indicators } \\
\hline Edmondson grade & III-IV =1, I II =2 \\
\hline BCLC stage & $0=1, A=2, B=3, C=4$ \\
\hline ALBI score & $<-2.60=1,-2.60 \sim-1.39=2,>-1.39=3$ \\
\hline PLR (before the matching) & $\leq 199.48=1,>199.48=2$ \\
\hline PLR (after the matching) & $\leq 197.74=1,>197.74=2$ \\
\hline NLR (before the matching) & $\leq 2.34=1,>2.34=2$ \\
\hline NLR (after the matching) & $\leq 2.26=1,>2.26=2$ \\
\hline capsule integrity & integrity $=0$, incomplete or without $=1$ \\
\hline microvascular invasion & no $=0$, yes $=1$ \\
\hline tumour embolus & no $=0$, yes $=1$ \\
\hline tumour size & $<5 \mathrm{~cm}=1, \geq 5 \mathrm{~cm}=2$ \\
\hline
\end{tabular}

\section{Results}

\section{Baseline data of the two groups before and after PSM}

Before and after PSM, the results showed that the BCLC stage, tumour size, ALBI score, and AST were not balanced between the two groups $(P<0.05)$. After PSM, there were 325 pairs included in the analysis, and all indicators of baseline data were comparable $(P>0.05)$, see Table 2 .

Table 2. Baseline data of the two groups

\begin{tabular}{lllllll}
\hline Index & \multicolumn{3}{l}{ Before PSM } & \multicolumn{5}{c}{ After PSM } \\
\cline { 2 - 7 } & $\begin{array}{l}\text { Group W } \\
(\mathrm{n}=325)\end{array}$ & $\begin{array}{l}\text { Group N } \\
(\mathrm{n}=492)\end{array}$ & $P$ & $\begin{array}{l}\text { Group W } \\
(\mathrm{n}=325)\end{array}$ & $\begin{array}{l}\text { Group N } \\
(\mathrm{n}=325)\end{array}$ & $P$ \\
\hline Age & & & 0.406 & & & 0.396 \\
$<60$ years & 276 & 407 & & 276 & 268 & \\
$\geq 60$ years & 49 & 85 & & 49 & 57 & \\
Male & 274 & 421 & 0.621 & 274 & 277 & 0.743 \\
Abnormal BMI & 131 & 181 & 0.311 & 131 & 120 & 0.376 \\
Liver cirrhosis & 145 & 215 & 0.796 & 145 & 143 & 0.875 \\
Hypertension & 33 & 36 & 0.154 & 33 & 23 & 0.162 \\
\hline
\end{tabular}




\begin{tabular}{|c|c|c|c|c|c|c|}
\hline \multirow[t]{2}{*}{ Index } & \multicolumn{3}{|c|}{ Before PSM } & \multicolumn{3}{|l|}{ After PSM } \\
\hline & $\begin{array}{l}\text { Group W } \\
(n=325)\end{array}$ & $\begin{array}{l}\text { Group N } \\
(\mathrm{n}=492)\end{array}$ & $P$ & $\begin{array}{l}\text { Group W } \\
(n=325)\end{array}$ & $\begin{array}{l}\text { Group N } \\
(n=325)\end{array}$ & $P$ \\
\hline Diabetes & 39 & 41 & 0.084 & 39 & 26 & 0.089 \\
\hline Abnormal albumin & 49 & 74 & 0.944 & 49 & 46 & 0.739 \\
\hline $\begin{array}{l}\text { Abnormal total } \\
\text { bilirubin }\end{array}$ & 60 & 110 & 0.192 & 60 & 65 & 0.619 \\
\hline Abnormal INR & 36 & 72 & 0.142 & 36 & 43 & 0.401 \\
\hline $\mathrm{AST}>40 \mathrm{U} / \mathrm{L}$ & 123 & 221 & 0.045 & 123 & 140 & 0.174 \\
\hline ALT> $>40 \mathrm{U} / \mathrm{L}$ & 109 & 186 & 0.214 & 109 & 120 & 0.366 \\
\hline $\mathrm{AFP} \geq 400 \mu \mathrm{g} / \mathrm{L}$ & 135 & 230 & 0.143 & 135 & 155 & 0.115 \\
\hline $\operatorname{HBeAg}(+)$ & 78 & 137 & 0.222 & 78 & 89 & 0.323 \\
\hline HBsAg $(+)$ & 288 & 425 & 0.349 & 288 & 277 & 0.201 \\
\hline HBV DNA & 204 & 317 & 0.629 & 204 & 210 & 0.625 \\
\hline Edmondson grade & & & 0.788 & & & 0.633 \\
\hline I-II & 192 & 286 & & 192 & 186 & \\
\hline III-IV & 133 & 206 & & 133 & 139 & \\
\hline BCLC stage & & & 0.023 & & & 0.211 \\
\hline 0 & 11 & 18 & & 11 & 13 & \\
\hline A & 179 & 217 & & 179 & 153 & \\
\hline B & 46 & 87 & & 46 & 49 & \\
\hline $\mathrm{C}$ & 89 & 170 & & 89 & 110 & \\
\hline ALBI score & & & 0.020 & & & 0.082 \\
\hline$<-2.60$ & 98 & 106 & & 98 & 73 & \\
\hline$-2.60 \sim-1.39$ & 221 & 374 & & 221 & 246 & \\
\hline$>-1.39$ & 6 & 12 & & 6 & 6 & \\
\hline PLR & & & 0.503 & & & 0.507 \\
\hline$\leq 199.48$ & 274 & 406 & & 274 & 280 & \\
\hline$>199.48$ & 51 & 86 & & 51 & 45 & \\
\hline NLR & & & 0.035 & & & 0.156 \\
\hline$\leq 2.34$ & 198 & 263 & & 188 & 170 & \\
\hline$>2.34$ & 127 & 229 & & 137 & 155 & \\
\hline $\begin{array}{l}\text { Incomplete or } \\
\text { without capsule }\end{array}$ & 116 & 194 & 0.281 & 116 & 121 & 0.684 \\
\hline $\begin{array}{l}\text { Microvascular } \\
\text { invasion }\end{array}$ & 153 & 206 & 0.142 & 153 & 145 & 0.529 \\
\hline Tumour embolus & 239 & 332 & 0.065 & 239 & 220 & 0.102 \\
\hline $\begin{array}{l}\text { Tumour size } \\
\geq 5 \mathrm{~cm}\end{array}$ & 202 & 343 & 0.025 & 202 & 219 & 0.163 \\
\hline
\end{tabular}

\section{Survival}

Before PSM, the median OS of patients in group $\mathrm{W}$ was 58 months, and the estimated OS rates at 1 year, 3 years, and 5 years were $81.50 \%, 65.20 \%$, and $49.70 \%$, respectively; and the median OS of patients in

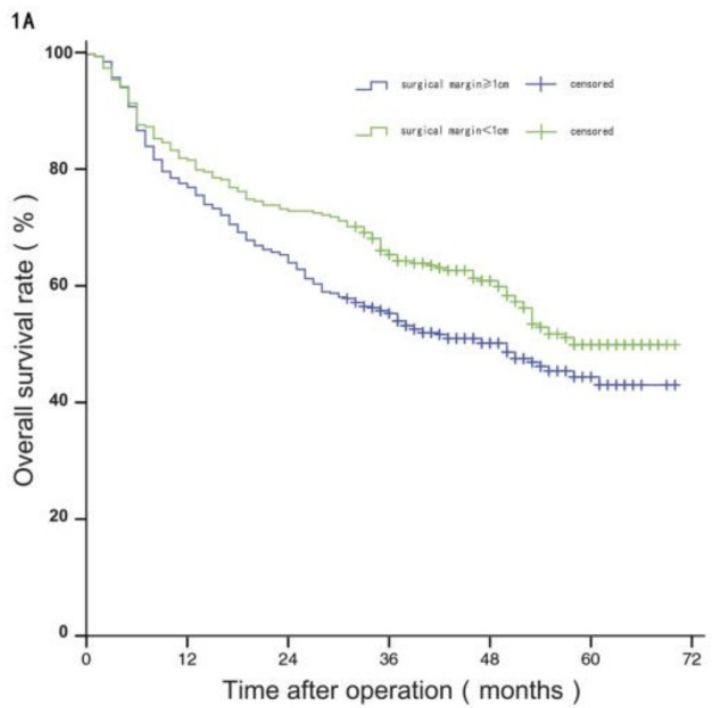

group $\mathrm{N}$ was 50 months, with estimated 1-year, 3 -year, and 5 -year OS of $75.80 \%, 55.30 \%$, and $44.40 \%$. The difference in OS between the two groups was statistically significant $(P<0.05)$. After PSM, the median OS of patients in group $\mathrm{W}$ was 57 months, and the estimated OS rates at 1 year, 3 years, and 5 years were $81.20 \%, 64.60 \%$, and $48.60 \%$, respectively; and the median OS of patients in group $\mathrm{N}$ was 50 months, with estimated 1-year, 3-year, and 5-year OS of $77.20 \%, 55.60 \%$, and $45.90 \%$. The difference in OS between the two groups was not statistically significant $(P>0.05)$, see Figure 1A and 1B.

Before PSM, the median PFS of patients in group $\mathrm{W}$ was 35 months, and the estimated PFS rates at 1 year, 3 years, and 5 years were $75.80 \%, 49.00 \%$, and $24.00 \%$, respectively; and the median PFS of patients in group $\mathrm{N}$ was 28 months, with estimated 1-year, 3-year, and 5-year PFS of $68.90 \%, 37.40 \%$, and $23.90 \%$. The difference in PFS between the two groups was statistically significant $(P<0.05)$. After PSM, the median PFS of patients in group W was 35 months, and the estimated PFS rates at 1 year, 3 years, and 5 years were $75.30 \%, 47.90 \%$, and $22.60 \%$, respectively; and the median PFS of patients in group $\mathrm{N}$ was 28 months, with estimated 1-year, 3-year, and 5-year PFS of $71.50 \%, 38.30 \%$, and $24.70 \%$. The difference in PFS between the two groups was not statistically significant $(P>0.05)$, see Figure $2 \mathrm{~A}$ and 2B.

\section{Factors influencing postoperative survival}

Before PSM, albumin, INR, AST, ALT, AFP, HBV DNA, Edmondson grade, BCLC stage, ALBI score, PLR, NLR, capsule integrity, microvascular invasion, tumour embolus, tumour size, and SM were the possible influencing factors in the univariate analysis $(P<0.05)$. After multivariate analysis, INR, AST,

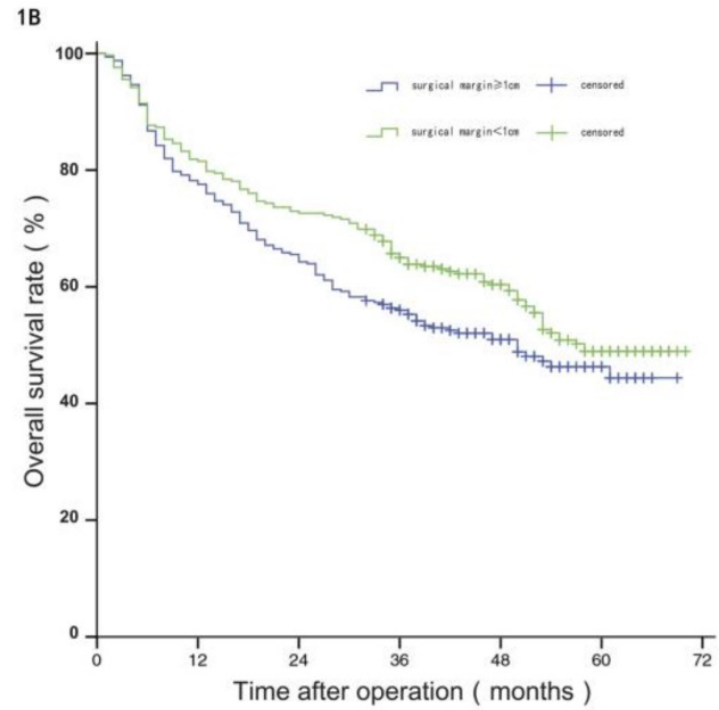

Figure 1. Comparison of OS between the two groups before and after propensity matching. 
capsule integrity, microvascular invasion, tumour embolus, and tumour size were kept as independent factors of the postoperative survival of patients $(P<0.05)$, see Table 3 .

Table 3. Univariate and multivariate survival analysis before PSM

\begin{tabular}{|c|c|c|c|c|c|c|}
\hline \multirow[t]{2}{*}{ Index } & \multicolumn{3}{|c|}{ Univariate analysis } & \multicolumn{3}{|c|}{ Multivariate analysis } \\
\hline & $P$ & $H R$ & $95 \% \mathrm{CI}$ & $P$ & $H R$ & $95 \% \mathrm{CI}$ \\
\hline age & 0.663 & & & & & \\
\hline sex & 0.137 & & & & & \\
\hline BMI & 0.136 & & & & & \\
\hline liver cirrhosis & 0.551 & & & & & \\
\hline hypertension & 0.744 & & & & & \\
\hline diabetes & 0.165 & & & & & \\
\hline albumin & 0.013 & 1.424 & $1.079-1.880$ & 0.429 & & \\
\hline total bilirubin & 0.895 & & & & & \\
\hline INR & 0.019 & 1.422 & $1.060-1.907$ & 0.049 & 1.364 & $1.001-1.859$ \\
\hline AST & $<0.001$ & 2.085 & $1.681-2.586$ & 0.028 & 1.339 & $1.033-1.736$ \\
\hline ALT & 0.019 & 1.300 & $1.044-1.618$ & 0.785 & & \\
\hline AFP & $<0.001$ & 1.573 & $1.270-1.948$ & 0.228 & & \\
\hline $\mathrm{HBeAg}$ & 0.102 & & & & & \\
\hline HBsAg & 0.369 & & & & & \\
\hline HBV DNA & 0.009 & 1.362 & $1.079-1.719$ & 0.456 & & \\
\hline Edmondson grade & $<0.001$ & 0.688 & $0.555-0.852$ & 0.229 & & \\
\hline BCLC stage & $<0.001$ & 2.052 & $1.820-2.313$ & 0.149 & & \\
\hline ALBI score & 0.007 & 1.394 & $1.095-1.775$ & 0.623 & & \\
\hline PLR & $<0.001$ & 1.931 & $1.500-2.485$ & 0.669 & & \\
\hline NLR & $<0.001$ & 1.784 & $1.439-2.211$ & 0.396 & & \\
\hline capsule integrity & $<0.001$ & 2.408 & $1.943-2.985$ & $<0.001$ & 1.861 & $1.486-2.330$ \\
\hline $\begin{array}{l}\text { microvascular } \\
\text { invasion }\end{array}$ & $<0.001$ & 2.103 & $1.671-2.646$ & 0.019 & 1.345 & $1.050-1.724$ \\
\hline tumour embolus & $<0.001$ & 3.592 & $2.895-4.458$ & 0.015 & 1.680 & $1.104-2.557$ \\
\hline tumour size & $<0.001$ & 2.965 & 2.246-3.915 & 0.004 & 1.603 & $1.162-2.211$ \\
\hline surgical margin & 0.042 & 0.792 & 0.633-0.992 & 0.095 & & \\
\hline
\end{tabular}

After PSM, albumin, INR, AST, AFP, HBV DNA, Edmondson grade, BCLC stage, ALBI score, PLR, NLR, capsule integrity, microvascular invasion, tumour embolus, and tumour size were identified as possible influencing factors in the univariate analysis

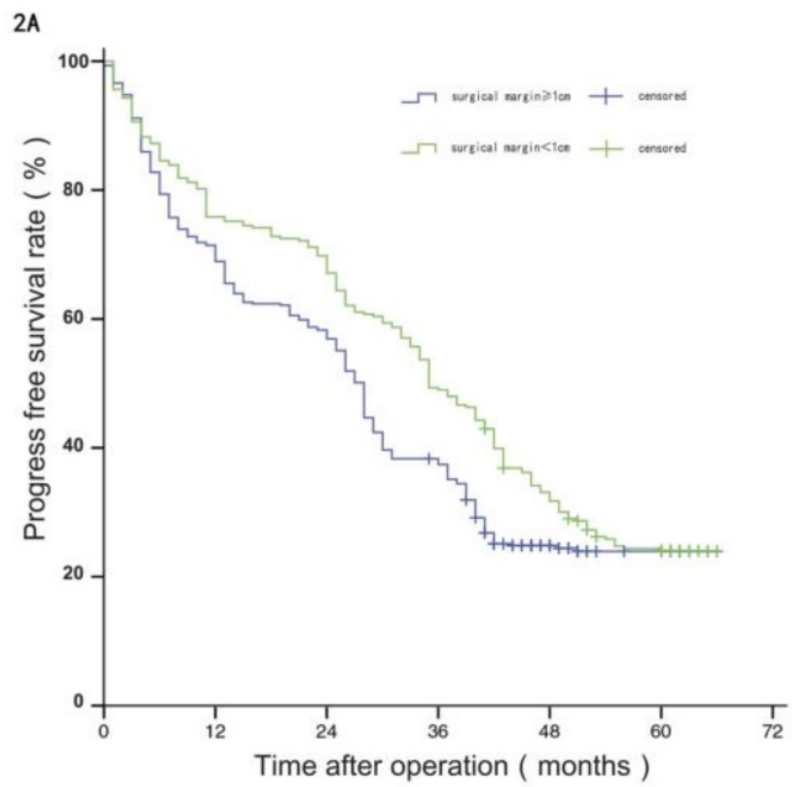

$(P<0.05)$. In the multivariate analysis, AST, capsule integrity, microvascular invasion, tumour embolus, and tumour size were kept as independent factors influencing the postoperative survival of patients $(P<0.05)$, see Table 4 .

\section{Discussion}

In a cohort study, PSM provides researchers with the ability to balance all the hypothesized risk factors between groups and makes it easy to check whether covariates are balanced [20]. PSM can reduce bias and improve the effectiveness of estimates by excluding unmatched study subjects [21, 22]. Whether the SM is an independent factor affecting the postoperative prognosis of HCC patients remains controversial. To exclude the interference of confounding factors and explore the effect of SM on the postoperative survival of HCC patients, this study used PSM to match the indicators of four categories, i.e., basic information, underlying diseases, tumour-related indicators, and routine haematological and biochemical indicators. In addition to the common indicators from previous studies, BMI, hypertension, and diabetes were also included. In clinical practice, a growing number of LC patients have abnormal BMI or underlying diseases, such as hypertension and diabetes. Abnormal BMI [23], diabetes [24, 25] and hypertension [26] are related to the incidence of LC; however, studies on the relationship between these three factors and the prognosis of HCC are still rare, so it is of certain practical significance to explore the relationship between these factors and the prognosis of HCC.

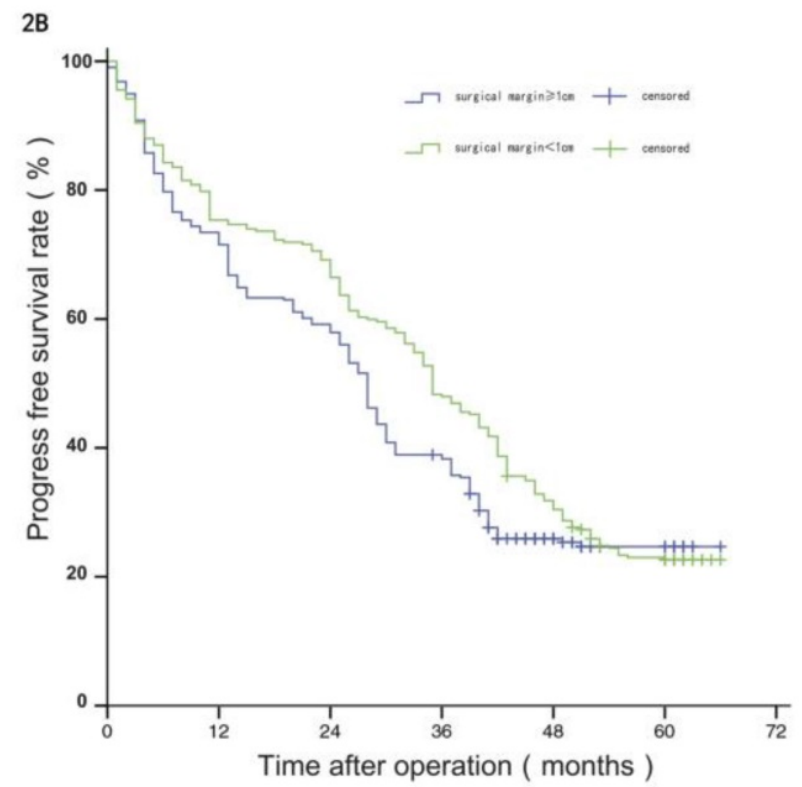

Figure 2. Comparison of RFS between the two groups before and after propensity matching. 
Table 4. Univariate and multivariate survival analysis after PSM

\begin{tabular}{|c|c|c|c|c|c|c|}
\hline \multirow[t]{2}{*}{ Index } & \multicolumn{3}{|c|}{ Univariate analysis } & \multicolumn{3}{|c|}{ Multivariate analysis } \\
\hline & $P$ & $H R$ & $95 \% \mathrm{CI}$ & $P$ & $H R$ & $95 \% \mathrm{CI}$ \\
\hline age & 0.574 & & & & & \\
\hline $\operatorname{sex}$ & 0.131 & & & & & \\
\hline BMI & 0.305 & & & & & \\
\hline liver cirrhosis & 0.413 & & & & & \\
\hline hypertension & 0.731 & & & & & \\
\hline diabetes & 0.653 & & & & & \\
\hline albumin & 0.189 & & & & & \\
\hline total bilirubin & 0.426 & & & & & \\
\hline INR & 0.019 & 1.422 & $1.060-1.907$ & 0.408 & & \\
\hline AST & $<0.001$ & 2.195 & $1.728-2.788$ & 0.013 & 1.394 & $1.071-1.814$ \\
\hline ALT & 0.153 & & & & & \\
\hline AFP & $<0.001$ & 1.573 & $1.240-1.995$ & 0.317 & & \\
\hline HBeAg & 0.311 & & & & & \\
\hline HBsAg & 0.177 & & & & & \\
\hline HBV DNA & 0.033 & 1.322 & $1.023-1.708$ & 0.731 & & \\
\hline Edmondson grade & 0.004 & 0.704 & $0.555-0.893$ & 0.693 & & \\
\hline BCLC stage & $<0.001$ & 2.071 & $1.818-2.360$ & 0.191 & & \\
\hline ALBI score & 0.021 & 1.359 & $1.046-1.764$ & 0.984 & & \\
\hline PLR & $<0.001$ & 1.097 & $1.002-1.204$ & 0.229 & & \\
\hline NLR & $<0.001$ & 1.772 & $1.396-2.251$ & 0.614 & & \\
\hline capsule integrity & $<0.001$ & 2.294 & $1.807-2.911$ & $<0.001$ & 1.752 & $1.366-2.247$ \\
\hline $\begin{array}{l}\text { microvascular } \\
\text { invasion }\end{array}$ & $<0.001$ & 2.103 & $1.671-2.646$ & 0.031 & 1.344 & $1.028-1.759$ \\
\hline tumour embolus & $<0.001$ & 3.768 & $2.963-4.790$ & 0.028 & 1.709 & $1.058-2.760$ \\
\hline tumour size & $<0.001$ & 3.068 & $2.256-4.172$ & 0.018 & 1.541 & $1.076-2.207$ \\
\hline surgical margin & 0.067 & & & & & \\
\hline
\end{tabular}

Our results showed that before PSM, SM had an impact on the survival of the patients. The PFS and OS of the patients in the $W$ group $(S M \geq 1 \mathrm{~cm}$ ) were longer than those in the $\mathrm{N}$ group $(\mathrm{SM}<1 \mathrm{~cm})$. After PSM, the differences in PFS and OS of the two groups were not significantly different. The results of this study, to some extent, explain the controversial conclusions from different studies in Taiwan [13, 17, 18]. Due to the presence of confounding factors, the baseline data of patients in two different groups may not be balanced, and such biases lead to different results in different studies.

The results of this study are different from the results of similar studies by Japanese scholars [11, 12]. Of the two studies in Japan on the effect of SM on the surgical prognosis of LC patients, one used tumour size $\leq 2 \mathrm{~cm}$ as the cut-off value, and the other used tumour size $\leq 4 \mathrm{~cm}$. One study showed that when the tumour size was greater than the cut-off value $(2 \mathrm{~cm})$, the SM did not affect the prognosis of patients [11]. However, the other study showed when the tumour size exceeds $4 \mathrm{~cm}, 10 \mathrm{~mm}$ of TW was inadequate to achieve curability and was linked to a recurrence [12]. Tumour size is a possible confounding factor, and this study also included tumour size as an indicator in PSM. However, the incidence of HCC in China is mostly related to $\mathrm{HBV}$ infection [3], while the incidence of HCC in Japan is closely related to hepatitis $\mathrm{C}$ virus (HCV) [27]. Japan emphasizes early screening for tumours, so the tumour size is usually smaller than that in China. Based on the margin-size characteristics of LC patients in south China, $5 \mathrm{~cm}$ was used as the cut-off value in this study.

Our results also differ from the results of a meta-analysis on the influence of SM on prognosis of patients [28]. That meta-analysis concluded that SM was related to the prognosis of patients. However, its seven included papers mostly lacked any description of whether the SM was negative. Five of them had small samples, and two papers did not give the follow-up time.

After confirming that there was no correlation between the SM and the prognosis of HCC patients, we further analysed the factors influencing the prognosis of HCC patients. To compare a real-world analysis and a cohort analysis on the factors affecting the postoperative prognosis of HCC patients, univariate and multivariate analyses were performed on the factors influencing the postoperative prognosis of HCC patients before and after PSM. The results showed that in the real-world analysis, the independent factors influencing the postoperative prognosis of patients with solitary HCC were INR, AST, capsule integrity, microvascular invasion, tumour embolus, and tumour size. After PSM, INR was excluded, but the other factors were retained. This result suggests that in a real-world study and a cohort study, the prognostic factors for patients with solitary HCC are different. The reason may be that the inclusion and screening criteria of cohort studies exclude some patients, so the prognostic factors of these patients are also excluded.

BCLC stage [8,9], ALBI score [10], and tumor differentiation [14] are generally considered independent factors affecting the postoperative prognosis of HCC patients. In our univariate analysis, there was also a statistically significant association between these factors and prognosis, but all three factors were ultimately excluded from the multivariate model. Edmondson grade was reported to predict the survival of patients with primary clear cell carcinoma of liver after curative resection [29], which was also a crucial predictor of survival in HCC without microvascular invasion [30]. Whether BCLC stage, ALBI score, and degree of tumour differentiation affect the postoperative prognosis of HCC patients requires more studies to confirm. AFP was also statistically significant in univariate analysis, but negatively in multivariate analysis. It is still controversial whether preoperative AFP level acts as an independent prognostic factor in patients undergoing resection for HCC [31,32].

Albumin has often been used as a factor in some scores or ratios to explore its relationship with the postoperative prognosis of HCC patients, such as the platelet-albumin-bilirubin score [33], ALBI score [34], and albumin-to-alkaline phosphatase ratio [35]. In this 
study, albumin was associated with prognosis in univariate analysis but was not included in the multivariate model. In the study by Wang et al. [36], PLR and NLR influenced the postoperative prognosis of HCC patients, and both were excluded from the final model in this study. In addition, our results showed that BMI, hypertension, and diabetes were unrelated to the postoperative prognosis of HCC patients.

Both INR and AST are measured in blood routine examination. INR can reflect the coagulation function of patients, and AST can reflect the degree of hepatic parenchymal damage. INR can be used as a predictor of disease severity in patients with colorectal cancer, but studies on the relationship between INR and postoperative prognosis of HCC patients are rare. The relationship between INR and the prognosis of HCC should be validated in studies with a large HCC sample size. The effect of AST level on the postoperative prognosis of HCC patients has also been confirmed in other studies. One study showed that patients with high AST had a short OS, which was consistent with the conclusions of this study [37]. The relationships between the prognosis of HCC patients and tumour capsule integrity [38, 39], microvascular invasion [40-42], and tumour embolus $[43,44]$ have been confirmed in many studies, and this study again confirmed the validity of these independent influencing factors in a LC population in southern China. The relationship between tumour size and the postoperative prognosis of HCC patients remains controversial. Some studies suggested that tumour size was associated with the prognosis of patients [16], which is consistent with the conclusion of this study, but other study showed that tumour size and prognosis were not correlated [45].

This study had a large sample size and controlled for confounding factors between groups through PSM, so the conclusions obtained were reliable. However, this study still had limitations because it was a single-centre study targeting HCC patients in southern China. Among patients with negative SMs, the SM did not affect the prognosis, and NLR, AST, capsule integrity, microvascular invasion, tumour embolus, and tumour size were independent influencing factors of the postoperative prognosis of HCC patients.

\section{Acknowledgements}

Funding was obtained through the following grants: National Natural Science Foundation of China (81660567, 81460516); The Key Research and Development Project of Guangxi (AA18221001, AB18050020); Guangxi BaGui Scholars' Special Fund (2019AQ20).

\section{Informed consent}

Written informed consent was obtained from each patient.

\section{Ethics approval}

This study was approved by the Ethics Committee of the Affiliated Cancer Hospital of Guangxi Medical University.

\section{Competing Interests}

The authors have declared that no competing interest exists.

\section{References}

1. Jemal A, Bray F, Center MM, Ferlay J, Ward E, Forman D. Global cancer statistics. CA Cancer J Clin. 2011; 61: 69-90.

2. Bray F, Ferlay J, Soerjomataram I, Siegel RL, Torre LA, Jemal A. Global cancer statistics 2018: GLOBOCAN estimates of incidence and mortality worldwide for 36 cancers in 185 countries. CA Cancer J Clin. 2018; 68: 394-424.

3. Chen W, Zheng R, Baade PD, Zhang S, Zeng H, Bray F, et al. Cancer statistics in China, 2015. CA Cancer J Clin. 2016; 66: 115-32.

4. Oikawa T. Cancer Stem cells and their cellular origins in primary liver and biliary tract cancers. Hepatology. 2016; 64: 645-51.

5. Reig M, Darnell A, Forner A, Rimola J, Ayuso C, Bruix J. Systemic therapy for hepatocellular carcinoma: the issue of treatment stage migration and registration of progression using the BCLC-refined RECIST. Semin Liver Dis. 2014; 34: 444-55.

6. Shen H, Zhong F, Zhang Y, Yu H, Liu Y, Qin L, et al. Transcriptome and proteome of human hepatocellular carcinoma reveal shared metastatic pathways with significant genes. Proteomics. 2015; 15: 1793-800.

7. Leung TWT, Tang AMY, Zee B, Lau WY, Lai PBS, Leung KL, et al. Construction of the Chinese University Prognostic Index for hepatocellular carcinoma and comparison with the TNM staging system, the Okuda staging system, and the Cancer of the Liver Italian Program staging system. Cancer. 2002; 94: 1760-9.

8. Liu PH, Hsu CY, Hsia CY, Lee YH, Chiou YY, Huang YH, et al. ALBI and PALBI grade predict survival for HCC across treatment modalities and BCLC stages in the MELD Era. J Gastroenterol Hepatol. 2017; 32: 879-86.

9. Zhang ZQ, Xiong L, Zhou JJ, Miao XY, Li QL, Wen Y, et al. Ability of the ALBI grade to predict posthepatectomy liver failure and long-term survival after liver resection for different BCLC stages of HCC. World Journal of Surgical Oncology. 2018; 16(1): 208.

10. Chan AW, Kumada T, Toyoda H, Tada T, Chong CC, Mo FK, et al. Integration of albumin-bilirubin (ALBI) score into Barcelona Clinic Liver Cancer (BCLC) system for hepatocellular carcinoma. J Gastroenterol Hepatol. 2016; 31: 1300-6.

11. Yoshida Y, Kanematsu T, Matsumata T, Takenaka K, Sugimachi K. Surgical margin and recurrence after resection of hepatocellular carcinoma in patients with cirrhosis. Further evaluation of limited hepatic resection. Ann Surg. 1989; 209: 297-301.

12. Masutani S, Sasaki Y, Imaoka S, Iwamoto S, Ohashi I, Kameyama M, et al. The prognostic significance of surgical margin in liver resection of patients with hepatocellular carcinoma. Arch Surg. 1994; 129: 1025-30.

13. Chau GY, Lui WY, Tsay SH, King KL, Loong CC, Chiu JH, et al. Prognostic significance of surgical margin in hepatocellular carcinoma resection: an analysis of 165 Childs' A patients. J Surg Oncol. 1997; 66: 122-6.

14. Shen J, Liu J, Li C, Wen T, Yan L, Yang J. The Impact of Tumor Differentiation on the Prognosis of HBV-Associated Solitary Hepatocellular Carcinoma Following Hepatectomy: A Propensity Score Matching Analysis. Dig Dis Sci. 2018; 63: 1962-9.

15. Wang $\mathrm{X}$, Wang $\mathrm{Z}, \mathrm{Wu} \mathrm{L}$. Combined measurements of tumor number and size helps estimate the outcome of resection of Barcelona clinic liver cancer stage B hepatocellular carcinoma. BMC Surg. 2016; 16: 22.

16. Mo HY, Zhong JH, Li LQ. Comment on tumor size as a prognostic factor for solitary HCC after resection. J Surg Oncol. 2016; 113: 593.

17. Jeng KS, Jeng WJ, Sheen IS, Lin CC, Lin CK. Is less than $5 \mathrm{~mm}$ as the narrowest surgical margin width in central resections of hepatocellular carcinoma justified? Am J Surg. 2013; 206: 64-71.

18. Lee KT, Wang SN, Su RW, Chen HY, Shi HY, Ker CG, et al. Is wider surgical margin justified for better clinical outcomes in patients with resectable hepatocellular carcinoma? J Formos Med Assoc. 2012; 111: 160-70.

19. Johnson PJ, Berhane S, Kagebayashi C, Satomura S, Teng M, Reeves HL, et al. Assessment of liver function in patients with hepatocellular carcinoma: a new evidence-based approach-the ALBI grade. J Clin Oncol. 2015; 33: 550-8.

20. D'Agostino RB, Jr. Propensity score methods for bias reduction in the comparison of a treatment to a non-randomized control group. Stat Med. 1998; 17: $2265-81$ 
21. Austin PC. Optimal caliper widths for propensity-score matching when estimating differences in means and differences in proportions in observational studies. Pharm Stat. 2011; 10: 150-61.

22. Sturmer T, Rothman KJ, Avorn J, Glynn RJ. Treatment effects in the presence of unmeasured confounding: dealing with observations in the tails of the propensity score distribution--a simulation study. Am J Epidemiol. 2010; 172: 843-54.

23. Yao KF, Ma M, Ding GY, Li ZM, Chen HL, Han B, et al. Meta-analysis reveals gender difference in the association of liver cancer incidence and excess BMI. Oncotarget. 2017; 8: 72959-71.

24. Lee MY, Lin KD, Hsiao PJ, Shin SJ. The association of diabetes mellitus with liver, colon, lung, and prostate cancer is independent of hypertension, hyperlipidemia, and gout in Taiwanese patients. Metabolism. 2012; 61: 242-9.

25. Giovannucci E, Harlan DM, Archer MC, Bergenstal RM, Gapstur SM, Habel LA, et al. Diabetes and cancer: a consensus report. Diabetes Care. 2010; 33: 1674-85.

26. Lee SH, Lee HA, Lee SS, Kim SE, Shim KN, Jung HK, et al. Clinical impact of pre-hypertension on the risk of cancer in male and female subjects. Sci Rep. 2020; 10: 9974

27. Hajarizadeh B, Grebely J, Dore GJ. Epidemiology and natural history of HCV infection. Nat Rev Gastroenterol Hepatol. 2013; 10: 553-62.

28. Zhong FP, Zhang YJ, Liu Y, Zou SB. Prognostic impact of surgical margin in patients with hepatocellular carcinoma: A meta-analysis. Medicine (Baltimore). 2017; 96: e8043.

29. Xu W, Ge P, Liao W, Ren J, Yang H, Xu H, Sang X, Lu X, Zhong S, Mao Y. Edmondson grade predicts survival of patients with primary clear cell carcinoma of liver after curative resection: A retrospective study with long-term follow-up. Asia Pac J Clin Oncol.2017;13:e312-e320.

30. Zhou L, Rui JA, Zhou WX, Wang SB, Chen SG, Qu Q. Edmondson-Steiner grade: A crucial predictor of recurrence and survival in hepatocellular carcinoma without microvascular invasion. Pathol Res Pract.2017;213:824-830.

31. Zhou PY, Yang CP, Tang Z, Yi Y, Liu WR, Tian MX, Huang JL, Gan W, Jiang XF, Liu G, Wang H, Tao CY, Fang Y, Qu WF, Zhou C, Guan RY, Sun BY, Zhou YF, Song SS, Ding ZB, Peng YF, Dai Z, Zhou J, Fan J, Gong GZ, Shi YH, Qiu SJ. Daily decrease of post-operative alpha-fetoprotein by $9 \%$ discriminates prognosis of HCC: A multicenter retrospective study. Aging (Albany NY). 2019;11:11111-11123.

32. Luo P, Wu S, Yu Y, Ming X, Li S, Zuo X, Tu J. Current Status and Perspective Biomarkers in AFP Negative HCC: Towards Screening for and Diagnosing Hepatocellular Carcinoma at an Earlier Stage.Pathol Oncol Res.2020;26:599-603.

33. Ho CHM, Chiang CL, Lee FAS, Choi HCW, Chan JCH, Yeung CSY, et al. Comparison of platelet-albumin-bilirubin (PALBI), albumin-bilirubin (ALBI), and child-pugh (CP) score for predicting of survival in advanced hcc patients receiving radiotherapy (RT). Oncotarget. 2018; 9: 28818-29.

34. Safiri S, Ayubi E. Comments on combining albumin-bilirubin score with future liver remnant predicts posthepatectomy liver failure in HBV-associated HCC patients. Liver Int. 2018; 38: 761.

35. Li Q, Lyu Z, Wang L, Li F, Yang Z, Ren W. Albumin-to-Alkaline Phosphatase Ratio Associates with Good Prognosis of Hepatitis B Virus-Positive HCC Patients. OncoTargets and Therapy. 2020; Volume 13: 2377-84

36. Wang D, Bai N, Hu X, OuYang XW, Yao L, Tao Y, et al. Preoperative inflammatory markers of NLR and PLR as indicators of poor prognosis in resectable HCC. PeerJ. 2019; 7: e7132.

37. Witjes $C D$, JN IJ, van der Eijk AA, Hansen $B E$, Verhoef $C$ de Man RA. Quantitative HBV DNA and AST are strong predictors for survival after HCC detection in chronic HBV patients. Neth J Med. 2011; 69: 508-13.

38. Iguchi T, Aishima S, Sanefuji K, Fujita N, Sugimachi K, Gion T, et al. Both fibrous capsule formation and extracapsular penetration are powerful predictors of poor survival in human hepatocellular carcinoma: a histological assessment of 365 patients in Japan. Ann Surg Oncol. 2009; 16: 2539-46.

39. Poon RT, Ng IO, Fan ST, Lai EC, Lo CM, Liu CL, et al. Clinicopathologic features of long-term survivors and disease-free survivors after resection of hepatocellular carcinoma: a study of a prospective cohort. J Clin Oncol. 2001; 19: $3037-44$

40. Chen ZH, Zhang XP, Wang H, Chai ZT, Sun JX, Guo WX, et al. Effect of microvascular invasion on the postoperative long-term prognosis of solitary small HCC: a systematic review and meta-analysis. HPB (Oxford). 2019; 21: 935-44.

41. Du M, Chen L, Zhao J, Tian F, Zeng H, Tan Y, et al. Microvascular invasion (MVI) is a poorer prognostic predictor for small hepatocellular carcinoma. BMC Cancer. 2014; 14: 38.

42. Zhao H, Hua Y, Lu Z, Gu S, Zhu L, Ji Y, et al. Prognostic value and preoperative predictors of microvascular invasion in solitary hepatocellular carcinoma $</=5 \mathrm{~cm}$ without macrovascular invasion. Oncotarget. 2017; 8: 61203-14.

43. Li SH, Wei W, Guo RP, Shi M, Guo ZX, Chen ZY, et al. Long-term outcomes after curative resection for patients with macroscopically solitary hepatocellular carcinoma without macrovascular invasion and an analysis of prognostic factors. Med Oncol. 2013; 30: 696.

44. Li SH, Guo ZX, Xiao CZ, Wei W, Shi M, Chen ZY, et al. Risk factors for early and late intrahepatic recurrence in patients with single hepatocellular carcinoma without macrovascular invasion after curative resection. Asian Pac J Cancer Prev. 2013; 14: 4759-63.
45. Levi Sandri GB, Spoletini G, Vennarecci G, Francone E, Abu Hilal M, Ettorre GM. Laparoscopic liver resection for large HCC: short- and long-term outcomes in relation to tumor size. Surg Endosc. 2018; 32: 4772-9. 